Theme: Oxygen Steelmaking

\title{
ULTRA-LOW PHOSPHORUS STEEL GRADE PRODUCTION IN ONE BATCH BOF BOTTOM BLOWING PROCESS*
}

\author{
Henrique Silva Furtado ${ }^{1}$ \\ Tathagata Bhattacharya ${ }^{2}$ \\ Hoyong Hwang ${ }^{3}$ \\ Odair Jose Kirmse ${ }^{4}$
}

\begin{abstract}
Concerning production of low phosphorus steel critical grades at ArcelorMittal Tubarão site, bottom blowing system plays a very important role. For those systems with independently controlled tuyeres, some non-uniform bottom blowing patterns seem to be promising in improving metal-slag mixing; however, based on computational fluid dynamics (CFD) results of ArcelorMittal Tubarão's post oxygen bottom blowing, this may not be generalized. Also, from industrial trials it became clear that higher the bottom blowing flow rate, the closer were the end point $P$ to the equilibrium. Despite this result an analysis of the apparent mass transfer coefficient has shown a week correlation with the classical power stir correlation suggesting a more complex kinetic limiting step for phosphorus removal.
\end{abstract}

Keywords: Dephosphorization; BOF process; Bottom blowing; CFD; Mixing.

Metallurgical Engineer, PhD, Specialist in Steelmaking, ArcelorMittal Tubarão, Serra, ES, Brazil. Metallurgical Engineer, PhD, Research Engineer, Steelmaking \& Refractories, ArcelorMittal Global $R \& D$, Chicago, IN, USA.

3 Metallurgical Engineer, PhD, Research Engineer, Steelmaking \& Refractories, ArcelorMittal Global $R \& D$, Chicago, IN, USA.

4 Metallurgical Engineer, MsC, Specialist in Steelmaking, ArcelorMittal Tubarão, Serra, ES, Brazil.

* Technical contribution to the $45^{\text {th }}$ Steelmaking Seminar, May $25^{\text {th }}-28^{\text {th }}, 2014$, Porto Alegre, RS, Brazil. 


\section{INTRODUCTION}

The ever increasing demand for better steel quality due to emerging markets such as advanced high strength steel (AHSS) calls for a lower phosphorus content in critical grades. It becomes more challenging when one considers a natural deterioration of raw material that tends to increase the phosphorus content in iron ore and iron alloys. Basic oxygen furnace (BOF) has been a very efficient process to remove $P$ from metal to slag [1]. From its classical hot metal $\mathrm{P}$ content of around $0.08 \%$, BOFs can easily reduce $\mathrm{P}$ content in steel to $0.020 \%$ ( $75 \%$ reduction) without any special treatments. However, for ultra-low $P$ steel (below 100ppm in products), BOFs must reduce $\mathrm{P}$ content below 70ppm. Under this circumstance, a regular BOF operation may not be sufficient.

Basically, there are two different routes that might accomplish a higher $\mathrm{P}$ removal in steelmaking. One is the hot metal pre-treatment developed mainly in Japan in the eighties [1] and more recently, improved as a duplex process [2], which aims at reducing initial $P$ input. The other is the BOF route that puts focus on $P$ removal during refining. This last one may be divided in a one step process, generally performed using a bottom-blown inert gas system [1], and a two-step process, also called double slag process [3].

Hot metal pretreatment requires a high investment, which is not feasible for Tubarão in a short or medium term. On the other hand, double slag practices reduce BOF productivity and put the steel shop in a risk of stopping operation due to slag pot overflow. This also requires special care to avoid atmospheric emissions. Therefore, one step BOF bottom blowing process is the natural choice for ArcelorMittal Tubarão site.

Phosphorus is well known to be removed from BOF metallic charge through slag [1]. A simple thermodynamic model can be expressed as follows [4]:

$$
2[\mathrm{P}]+5[\mathrm{O}] \leftrightarrow\left(\mathrm{P}_{2} \mathrm{O}_{5}\right) \quad \Delta G^{0}=A+B \cdot T
$$

In this case, bracket refers to metal and parenthesis refers to liquid slag. $\Delta G^{0}$ is the Gibbs free energy at a reference state; $T$ is the temperature and $A$ and $B$ are constants (the first one is negative and the second one is positive, respectively). Its thermodynamic equilibrium constant at a given temperature can be equated by the following equation:

$$
\operatorname{Ln}\left(K_{P}\right)=\frac{a_{P_{2} O_{5}}}{h_{P}^{2} \cdot h_{O}^{5}}=\frac{A}{R \cdot T}+\frac{B}{R}
$$

where, the letter " $a$ " refers to a pure liquid $\mathrm{P}_{2} \mathrm{O}_{5}$ reference state activity; " $h$ " refers to a $\mathrm{Fe}-1 \mathrm{wt} \% \mathrm{X}$ reference state activity (wt \% means weight percent). In this case, $\mathrm{X}$ can be $P$ and $O$, respectively, and $R$ is the gas constant.

Equation 2 can be rewritten using activity coefficient and percentage of components involved in reaction 1 as follows:

$$
\operatorname{Ln}\left(\frac{(w t \% P)}{[w t \% P]^{2}}\right)=\frac{A}{R \cdot T}+\frac{B}{R}+2 \cdot \ln \left(\left[f_{P}\right]\right)+5 \cdot \ln \left(\left[h_{O}\right]\right)-\ln \left(\left(\gamma_{P_{2} O_{5}}\right)\right)-\ln (\eta)
$$

where, $\left[f_{P}\right]$ is the activity coefficient of $P$ in the metal; $\left(\gamma_{P_{2} O_{5}}\right)$ is the activity coefficient of $\mathrm{P}$ oxide in slag and $\eta$ is a stoichiometric constant. The ratio in the left hand side (inside logarithm function) of equation 3 is called phosphorus equilibrium partition coefficient $\left(L_{P}\right)$.

\footnotetext{
* Technical contribution to the $45^{\text {th }}$ Steelmaking Seminar, May $25^{\text {th }}-28^{\text {th }}, 2014$, Porto Alegre, RS, Brazil.
} 
From equation 3, a number of comments can be made on the influence of temperature and activity of constituents on the partition coefficient, $L_{p}$. One can infer that low temperature, low activity coefficient of $P$ oxide in slag and high $P$ activity coefficient in metal, and high oxygen activity in metal may improve $L_{p}$. On the other hand, $L_{p}$ would be negatively impacted if the temperature is higher.

Activity coefficient of $P$ in the metal is dependent on charge composition (mainly $C$, $\mathrm{Si}, \mathrm{Mn}$ and $\mathrm{O}$ ). Besides $\mathrm{Mn}$ which reduces $f_{P}$, all other elements tend to increase it, thereby affecting $L_{P}[1]$ positively.

From slag side, there is a consensus that an increase in basic oxides content in it reduces $\gamma_{P_{2} O_{5}}$ and therefore improves $L_{p}$. [5-7]. However, very high basicity $\left(\mathrm{CaO} / \mathrm{SiO}_{2}\right)$ may induce precipitation of solid phases that cannot absorb $P[8,9]$ promoting a reduction of $L_{P}$. Also, an increase in iron oxide in slag up to a certain level that does not reduce its basic oxide activity has shown to be effective in reducing $\gamma_{P_{2} \mathrm{O}_{5}}[6,7]$.

Phosphorus partition coefficient (at equilibrium or not) is a very suitable parameter for multi-component metal-slag equilibrium experiments due to its simplicity in being measured. It can also be found in literature written in different way $[10,11]$. The most common form is as follows:

$L_{P}=\frac{(w t \% P)}{[w t \% P]}$

Also, it is very simple to be incorporated in $\mathrm{P}$ mass balance as presented below:

$[w t \% P]=\left(H M \cdot w t \% P_{H M}+\sum \operatorname{Scrap} \cdot w t \% P_{\text {iscrap }}\right) /\left(\right.$ Steel $\left.+\operatorname{Slag} \cdot L_{P}\right)$

where, HM , Scrap, Steel and Slag are weight of hot metal, scrap, steel and slag, respectively and $w t \% P_{H M}, w t \% P_{i s c r a p}$ are hot metal and scrap $\mathrm{P}$ content, respectively.

From equation 5 , one may infer that in order to achieve low $\mathrm{P}$ content in steel at the end of BOF process, one needs low $P$ input from total charge, large slag volume and high $\mathrm{P}$ partition coefficient. Therefore, a well-defined equilibrium model for $L_{p}$ based on chemistry of metal and slag, and temperature is essential to improve $P$ removal during BOF process. However, models for $L_{p}$ developed from experiments resulted in a quite scattered values and to date no single correlation is universally accepted and validated in all slag system [7].

A more deep insight into the thermodynamic of $P$ removal may be obtained from computational thermodynamics [7]. Different from linear models, it generally processes a comprehensive, critically analyzed database, originated from different experiments, into semi-empirical models for free energy [7,12-14]. Therefore, more consistent results are expected, especially when one aims at extrapolating calculation to domains not yet covered by experiments. In this context, ArcelorMittal implemented this concept into a proprietary software called CEQCSI (Chemical EQuilibrium Calculation for Steel Industry), which was reviewed recently to include a generalized central atom model to accomplish $\mathrm{P}$ equilibrium calculation between metal and slag [7,12-14].

Motivated by the assumption that at the end of blow $P$ in steel is far from its metalslag equilibrium concentration [15], a plant with already installed independently controlled bottom blowing tuyeres started up to investigate special biased bottom injection schemes [16]. It might be a good idea to reduce $P$ significantly and achieve ultra-low $P$ steel grade in one step with lower flow rate [16].

* Technical contribution to the $45^{\text {th }}$ Steelmaking Seminar, May $25^{\text {th }}-28^{\text {th }}, 2014$, Porto Alegre, RS, Brazil. 
The purpose of present work is to discuss results from computational fluid dynamics (CFD), thermodynamic predictions and plant measurements aiming at maximize $P$ removal in one step bottom blowing BOF process at ArcelorMittal Tubarão site, maximizing post oxygen argon bottom blowing (POABB) metal-slag mixing.

\section{MATERIALS AND METHODS}

Prior to industrial trials, CFD were performed to simulate the mixing inside the metal bath as influenced by various bottom blowing recipes. This has been a very important tool to investigate the fluid dynamics inside BOF vessels [17].

CFD analysis was performed using Ansys Fluent $\AA$-- a commercial software [18] accepted widely as industry standard. The geometry of the inner profile of the vessel (Figure 1a) was approximated using the available laser scan. Ansys Meshing was used to discretize the domain and obtain a desired mesh that will produce a meshindependent solution.

Momentum transfer from the injected argon bubbles to the liquid steel was modeled using an Eulerian-Lagrangian approach where the bubbles were treated as DPM [18] (discrete phase model) particles. A suitable drag law was used to obtain the momentum exchange term between bubbles and the continuous phase (liquid steel). For liquid steel, the continuity and momentum equations were solved in addition to a suitable turbulence model $(k-\varepsilon)$. A steady-state velocity field in liquid steel bath was first obtained. Afterwards, a species transport equation was solved on this frozen velocity field with a blob of initial tracer being positioned at the center of bath (Figure 1b) at time zero. This tracer was then dispersed by the metal velocity field as time progressed. Its concentration evolution was then monitored at different locations of the domain as a function of time until a complete homogenization was obtained.

In order to compare and characterize different bottom blowing schemes, a mixing index $(M)$ was developed with the following definition:

$$
M=1-\frac{\sigma(t)}{\sigma_{0}}
$$

where $\sigma(t)$ is the standard deviation of tracer concentration in the domain at any time $\mathrm{t}$ and $\sigma_{0}$ is the same quantity at time zero (completely unmixed condition). The bottom blowing recipes used in the CFD simulations are presented in Table 1.
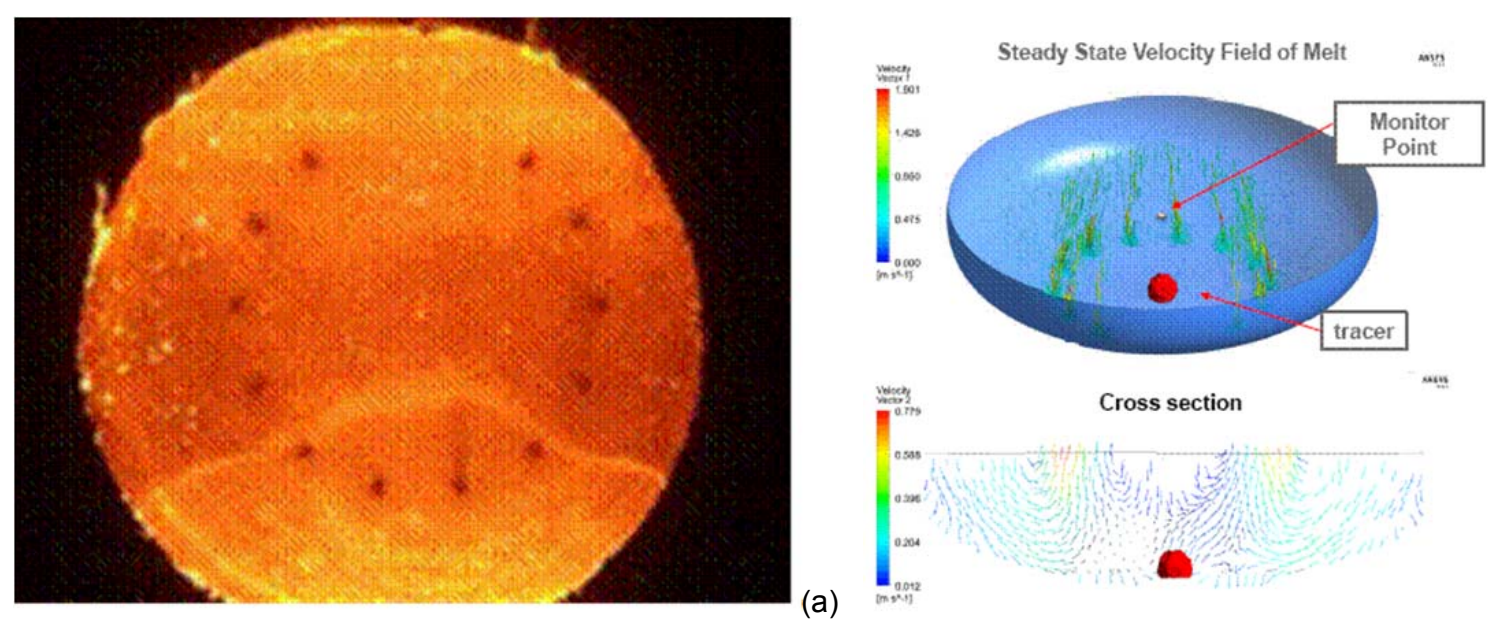

Figure 1. (a) Tubarão converter bottom tuyeres configuration and (b) an example of CFD simulation.

* Technical contribution to the $45^{\text {th }}$ Steelmaking Seminar, May $25^{\text {th }}-28^{\text {th }}, 2014$, Porto Alegre, RS, Brazil. 
Based on previous CFD predictions, some plant trials were performed. Then thermodynamic calculations using ArcelorMittal software (CEQSCI) were done. Finally a mass transfer coefficient, calculated using equilibrium $P$ content in steel, was determined and the $P$ removal rate controlling step was discussed

During industrial trials, no special procedure was performed other than POABB. Steel samples, temperature and oxygen activity were taken at the end of blow and after POABB. Slag samples were collected only during tapping due to safety reasons. The range of total bottom blowing flow rate was from $600 \mathrm{Nm}^{3} / \mathrm{hr}$ to $1000 \mathrm{Nm}^{3} / \mathrm{hr}$ and the time of POABB were around 2 minutes to minimize heat losses.

Table 1. Various bottom blowing recipes per tuyeres

\begin{tabular}{|c|c|c|c|c|c|c|c|}
\hline \multicolumn{7}{|c|}{ Argon flow rate $\left(\mathrm{Nm}^{3} / \mathrm{hr}\right)$} \\
\hline Tuyere N $^{\circ}$ & $\# 1$ & $\# 2$ & $\# 3$ & $\# 4$ & $\# 5$ & $\# 6$ & $\# 7$ \\
\hline 1 & 83.3 & 41.7 & 111.1 & 111.1 & 45 & 35 & 100 \\
\hline 2 & 83.3 & 41.7 & 55.6 & 111.1 & 75 & 45 & 100 \\
\hline 3 & 83.3 & 41.7 & 111.1 & 0 & 75 & 55 & 100 \\
\hline 4 & 83.3 & 41.7 & 55.6 & 111.1 & 75 & 64 & 100 \\
\hline 5 & 83.3 & 41.7 & 111.1 & 111.1 & 75 & 55 & 100 \\
\hline 6 & 83.3 & 41.7 & 55.6 & 0 & 45 & 45 & 100 \\
\hline 7 & 83.3 & 41.7 & 111.1 & 111.1 & 45 & 36 & 100 \\
\hline 8 & 83.3 & 41.7 & 55.6 & 111.1 & 30 & 45 & 100 \\
\hline 9 & 83.3 & 41.7 & 111.1 & 0 & 30 & 55 & 100 \\
\hline 10 & 83.3 & 41.7 & 55.6 & 111.1 & 30 & 64 & 100 \\
\hline 11 & 83.3 & 41.7 & 111.1 & 111.1 & 30 & 55 & 100 \\
\hline 12 & 83.3 & 41.7 & 55.6 & 111.1 & 45 & 45 & 100 \\
\hline Total $\left(\mathrm{Nm}^{3} / \mathrm{hr}\right)$ & 1000 & 500 & 1000 & 1000 & 600 & 600 & 1200 \\
\hline
\end{tabular}

\section{RESULTS AND DISCUSSION}

\subsection{CFD Analysis of Tubarão's Inert Gas Bottom Blowing Injection Process}

Figure 2 depicts a three dimensional view of the tracer dispersion in the bath due to mixing induced by argon injection through twelve plugs from the bottom.

Using equation 6 and results of tracer concentration in different parts of the domain it was possible to build a mixing curve as a function of time as shown in Figure 3.

Some conclusions can be made from Figure 3. All recipes can be clearly grouped into two categories - recipes in group 1 (recipe \# 1, 2, 3, 4 \& 7) show better mixing performance as compared to recipes in group 2 (recipe \# 5,6). Group 1 recipes included recipes where all plugs get equal flow rates, a special recipe where the flow rates varied alternately $(1 \mathrm{X}, 2 \mathrm{X}, 1 \mathrm{X}, 2 \mathrm{X}$..etc.) in adjacent plugs and also a special case where two plugs were blocked. The CFD result reported minor changes in the mixing times between these cases and hence they were grouped in one category. Nonetheless, recipe 3 reported the shortest mixing time.

It is also interesting to note from Figure 3 that in group 1, recipe 2 (low and constant flow rate) reported a low mixing time, very similar to recipes 1 and 7 (high constant flow rate). Additionally, contrary to general belief and findings from other study [16], another group that contains biased flow rates (recipes $5 \& 6$ ) with a little higher total flow rate than recipe 2 did not produce better mixing. Therefore, a biased flow rate is always not beneficial and the findings reported here or elsewhere [16] cannot be generalized. Instead, a case by case approach needs to be taken to characterize the

* Technical contribution to the $45^{\text {th }}$ Steelmaking Seminar, May $25^{\text {th }}-28^{\text {th }}, 2014$, Porto Alegre, RS, Brazil. 
systems as every bottom stirring system is different and the results are regime dependent.
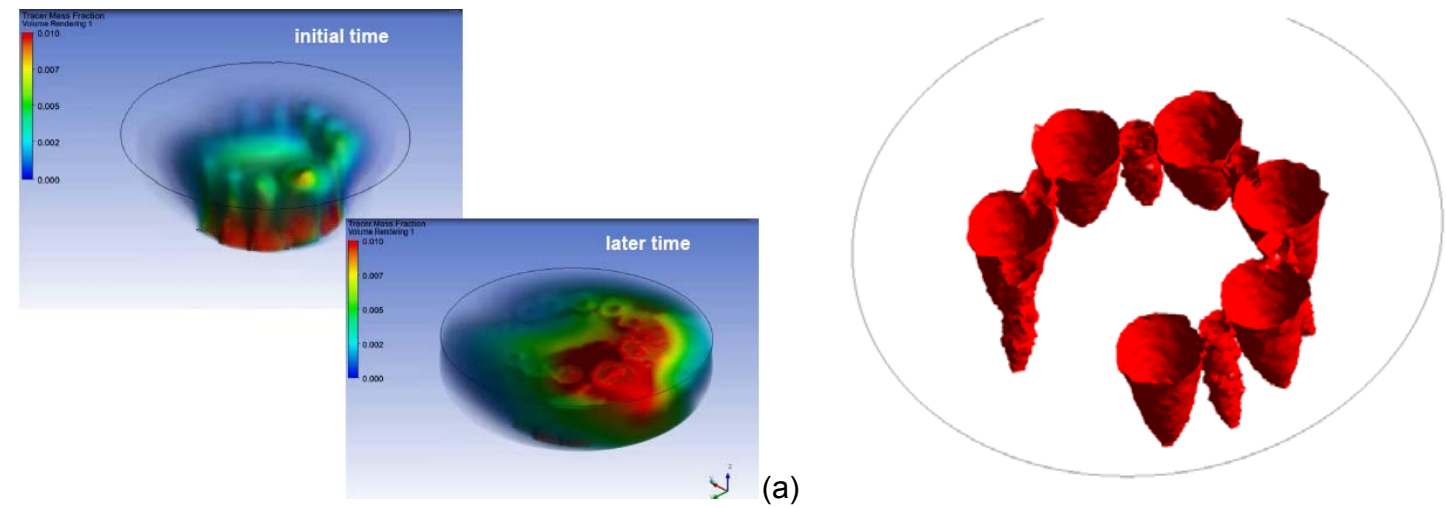

(a)

(b)

Figure 2. (a) Tracer dispersion as time evolves: a 3D view (b) a typical argon gas plume inside the bath for recipe \# 3 obtained by plotting an iso-surface of argon concentration.

The above results can be explained from an understanding of the mass transfer in the bath as influenced by gas plumes from bottom blowing. As per Dankwerts' surface renewal theory [19], the interfacial mass transfer coefficient for turbulent flow is given by:

$$
K_{S}=\sqrt{\frac{D}{t_{L}}}=\sqrt{\frac{D \cdot u^{\prime}}{0.2 \cdot b}}
$$

where $D$ is the Diffusivity of any species; $t_{L}$ the Lagrangian time scale; $b$ a half width of gas plume on free surface and $u$ ' a typical near free surface radial turbulent velocity.

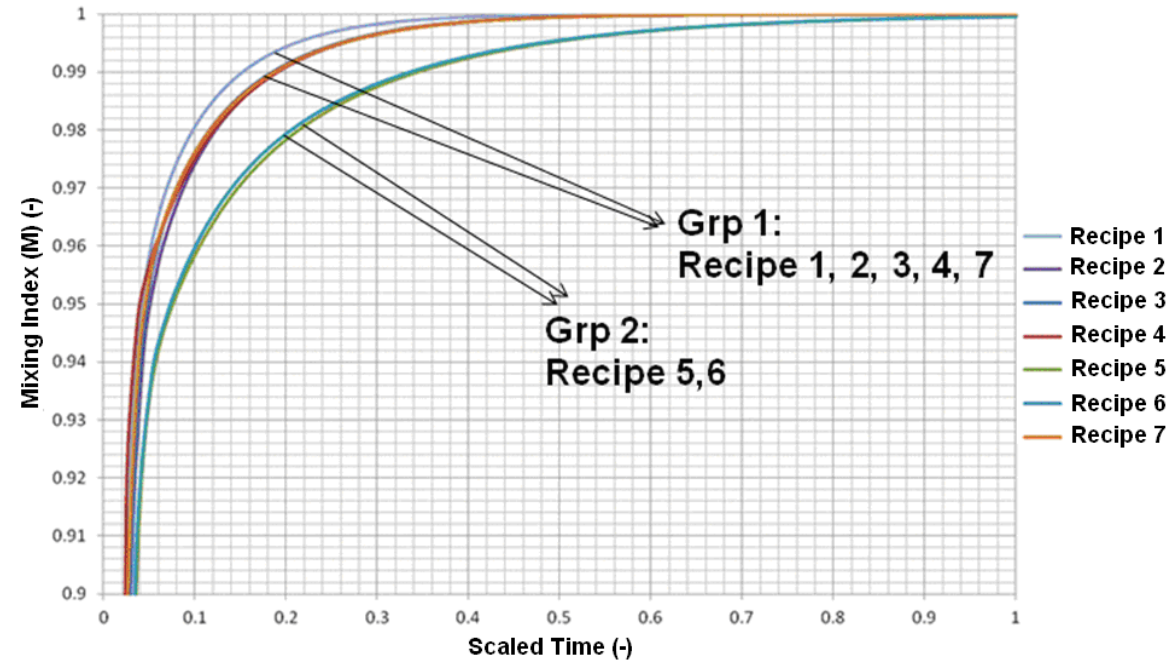

Figure 3. Tracer curves for all recipes from Table 1.

The reader is referred to Figure $2 b$ for a representation of a typical gas plume for one of the recipes. From equation 7 , one can infer that the mass transfer coefficient $K_{s}$ will increase as $u$ ' goes up (high turbulence kinetic energy (TKE) or velocity) and $b$ goes down (stable unmerged plume is better; if plumes merge, $b$ will increase). Also, mass transfer amount is proportional to interfacial area, so a bottom blowing configuration or recipe that produces more high velocity interfacial-area will be highly efficient in mixing. As can be observed in Table II, group 1 recipes should have

* Technical contribution to the $45^{\text {th }}$ Steelmaking Seminar, May $25^{\text {th }}-28^{\text {th }}$, 2014, Porto Alegre, RS, Brazil. 


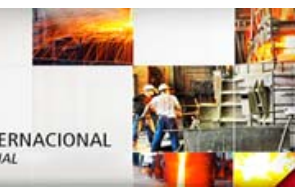

higher $K_{s}$ than group 2 recipes, which were earlier confirmed from tracer dispersion CFD simulations. However, when one compares recipe 2 from group 1 and recipe 6 from group 2, one sees that the major difference is on total interfacial area. That suggests that total interfacial area may have a stronger effect on mixing than TKE.

Table 2. Summary of total TKE and total interfacial area inside the bath from CFD alculations

\begin{tabular}{|c|c|c|}
\hline Recipes & Total TKE $(\mathrm{J} / \mathrm{Kg})\left(^{*}\right)$ & Total interfacial area $\left(\mathrm{m}^{2}\right)\left({ }^{*}\right)$ \\
\hline$\# 1$ & 5849.63 & 22.88 \\
\hline$\# 2$ & 4197.84 & 18.13 \\
\hline$\# 3$ & 5895.08 & 21.79 \\
\hline$\# 4$ & 4546.19 & 17.39 \\
\hline$\# 5$ & 4011.99 & 14.94 \\
\hline$\# 6$ & 4206.58 & 15.60 \\
\hline$\# 7$ & 5635.15 & 21.68 \\
\hline
\end{tabular}

(*)obtained on an iso-surface inside the bath having $0.5 \mathrm{~m} / \mathrm{s}$ velocity)

\subsection{Plant Experiments with POABB Process at ArcelorMittal Tubarão Site}

Based on CFD results, industrial trials were performed using a constant flow rate during POABB. In table III, one can observe a general statistics on trials compared with regular bottom blowing process and top blowing process. It is clear that the uses POABB can improve $L p$ significantly.

Table 3. Statistics of industrial trials

\begin{tabular}{|c|c|c|c|}
\hline & $\begin{array}{l}\text { Top blow, } \\
\text { (Lp) }\end{array}$ & $\begin{array}{l}\text { Combined blow - } \\
\text { End blow, (Lp) }\end{array}$ & $\begin{array}{l}\text { POABB, } \\
\text { (Lp) }\end{array}$ \\
\hline Average & 58 & 74 & 101 \\
\hline Stdev & 16 & 18 & 22 \\
\hline
\end{tabular}

Considering $\mathrm{P}$ mass balance as represented by equation 5 , one may build Figure 4 for a range of input $P$ and a maximum of slag volume possible to work without risk of slopping at Tubarão site. As can be seen, from average results of the trials $\left(L_{P} \sim 100\right)$, it might be possible to achieve 70ppm $\mathrm{P}$ at the end of blow for an input $\mathrm{P}$ below $0.09 \%$. However, according with Figure 5, low temperature and reduction of $L p$ scattering is required to obtain a consistent result.

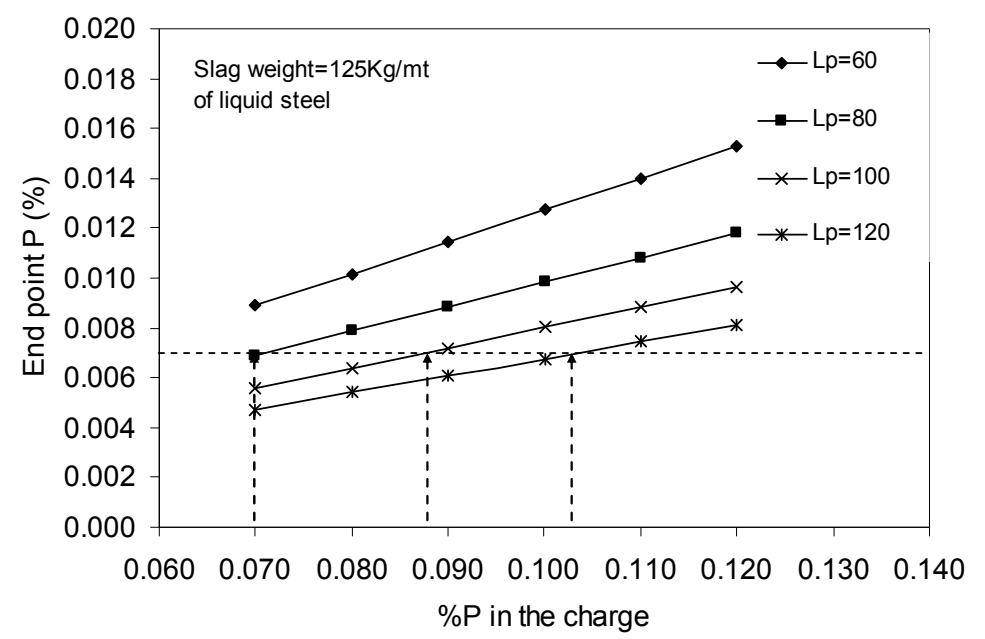

Figure 4. Effect of $L p$ and input $\mathrm{P}$ on end point $\mathrm{P}$ as predicted by equation 5 .

\footnotetext{
* Technical contribution to the $45^{\text {th }}$ Steelmaking Seminar, May $25^{\text {th }}-28^{\text {th }}, 2014$, Porto Alegre, RS,
} Brazil. 
In fact, when results of $L p$ from POABB trials are compared with equilibrium conditions (Figure 5), one can observe that there is still some room for improvements, especially at lower temperature. This may be possible though the maximization of metal-slag $P$ removal kinetic.

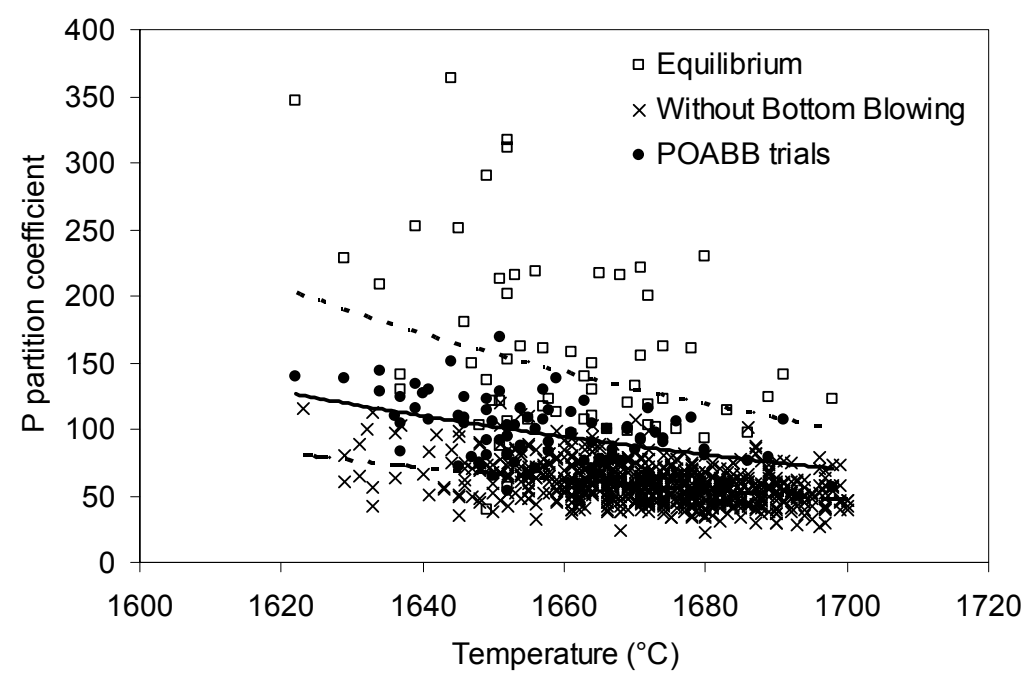

Figure 5. Effect of temperature on $\mathrm{P}$ partition coefficient at BOF end point.

In order to better understand the kinetics of post-oxygen mixing, a general formulation based on first-order kinetics could be used as follows:

$$
\frac{d[P]}{d t}=k_{a} \cdot\left\{[P]-[P]_{e q}\right\}
$$

where, $t$ is time; $k_{a}$ is the apparent mass transfer coefficient and $[P]_{e q}$ is the $\mathrm{P}$ at metal slag interface under equilibrium.

This model considers some types of rate limiting steps in slag/metal reaction kinetics, namely metal mass transfer; slag phase mass transfer; slag-metal mass transfer and reaction rate.

Generally, for high temperature, the reaction rate is high and it is assumed that metal side mass transfer is the rate limiting step. Under this assumption, an analysis could be done by fitting the mass transfer coefficient with the available stirring power due to argon injection as follows:

$$
\varepsilon=14.23 \cdot \frac{Q \cdot T}{W} \cdot \log \left(1+\frac{H}{1.48}\right)
$$

where, $\varepsilon$ is stirring power; $Q$ is the gas flow rate; $H$ is the bath height; $T$ is the temperature and $W$ is the steel weight.

As can be seen from Figure 6 (trial results), $k_{a}$ has a weak, but positive correlation with stirring power, consistent with previous CFD results that has shown a small differences in TKE and total interface area between low flow rate recipe and the high flow rate one (both from group 1), although not able to differentiate their mixing time magnitudes. This week correlation suggests that another rate limiting step may be in action. An alternative hypothesis could be a slag phase mass transfer limitation.

* Technical contribution to the $45^{\text {th }}$ Steelmaking Seminar, May $25^{\text {th }}-28^{\text {th }}, 2014$, Porto Alegre, RS, Brazil. 

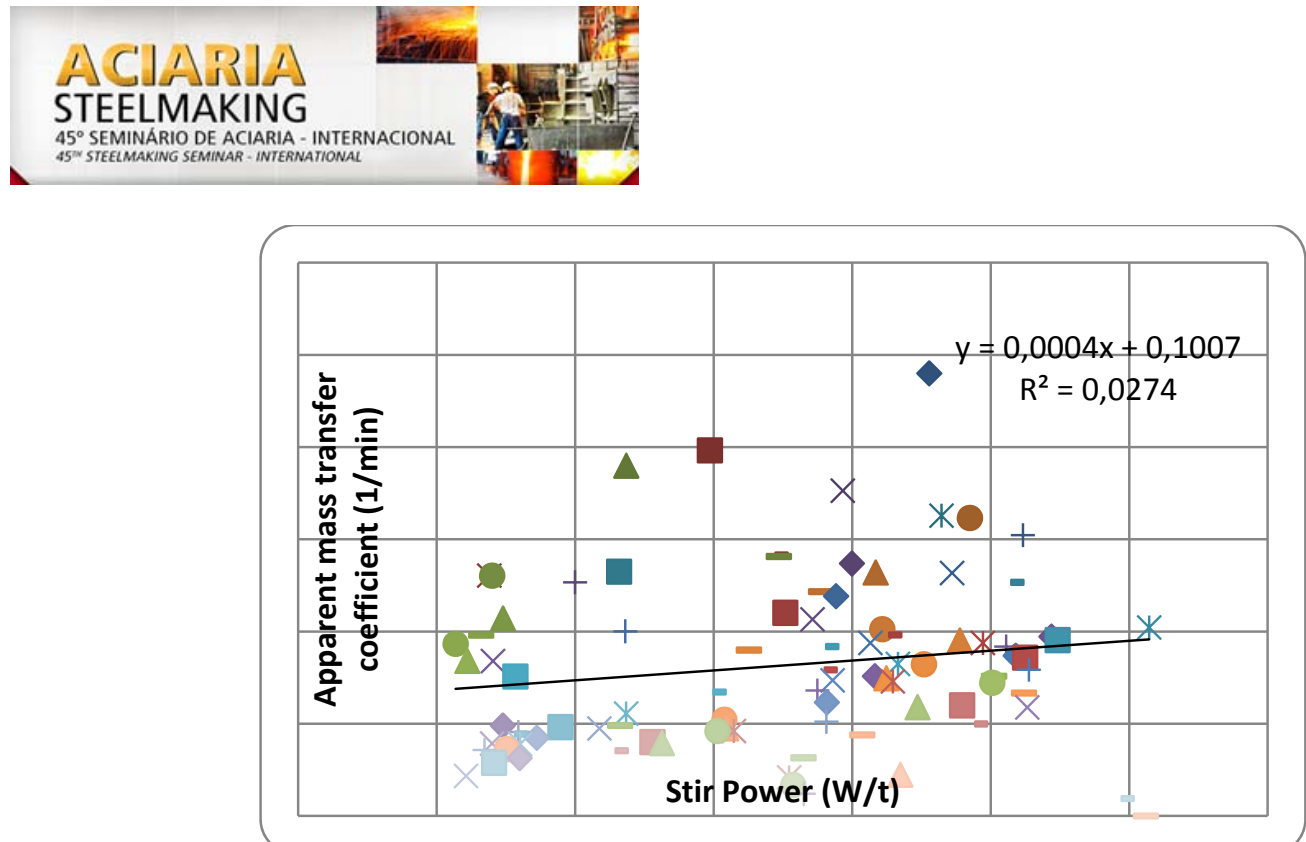

Figure 6. Apparent mass transfer coefficient as function of stir power.

In order to check slag phase mass transfer limit step for $P$ removal, slag viscosity was calculated with Urbain's model [1]. It is expected to have a higher mass transfer coefficient for low slag viscosity (higher slag fluidity). However, the trial result shows an inverse correlation (Figure 7). Therefore, we may conclude that slag phase mass transfer may not play an important role in $P$ removal kinetic.

The actual apparent mass transfer coefficient was observed to be correlated with slag chemistry and temperature (Figure 8). This suggests that a more complex kinetic limiting step for phosphorus removal might be taking place. Two hypothesis might be done: one inspired in the work of Manning and Fruehan [20], that links mass transfer parameter to the dynamic of interface, where oxygen flux across the interface might reduce interfacial tension and, under intense interface turbulence, might generate emulsification, increasing both interfacial area and mass transfer coefficient. However, this would report $k_{a}$ to be very sensitive to POABB flow rate, which was not observed (Figure 6); the second one is a chemical reaction limiting step. In fact regression formula from Figure 8 gives some indication that this might be consistent as an increase in temperature has an effect of reducing $k_{a}$. However a deeper analysis is required in order to better understand the role of slag components on $k_{a}$.

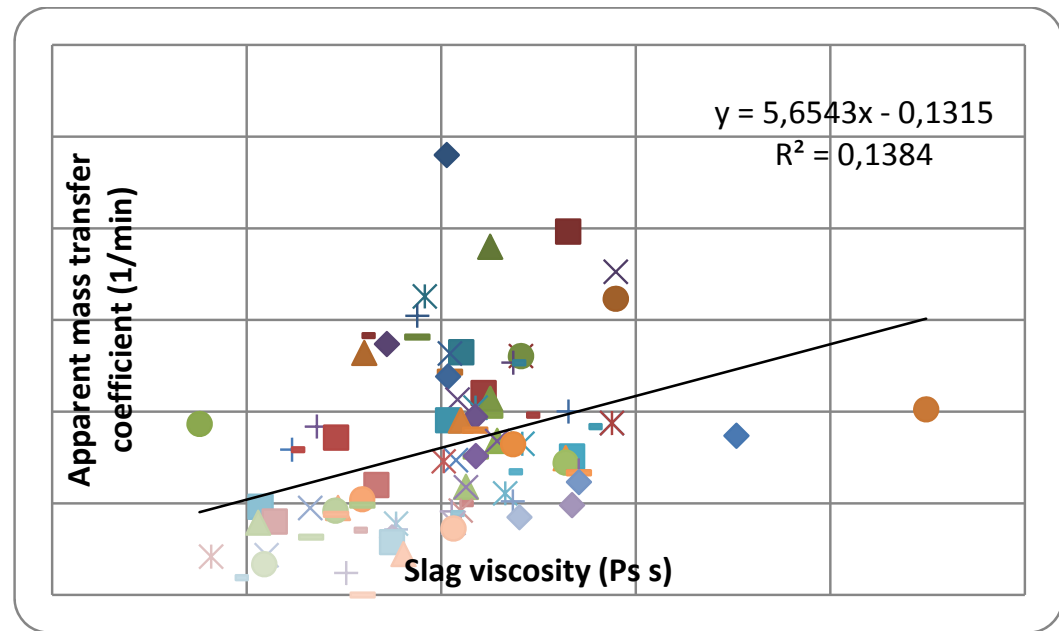

Figure 7. Apparent mass transfer coefficient as a function of slag viscosity.

* Technical contribution to the $45^{\text {th }}$ Steelmaking Seminar, May $25^{\text {th }}-28^{\text {th }}, 2014$, Porto Alegre, RS, Brazil. 

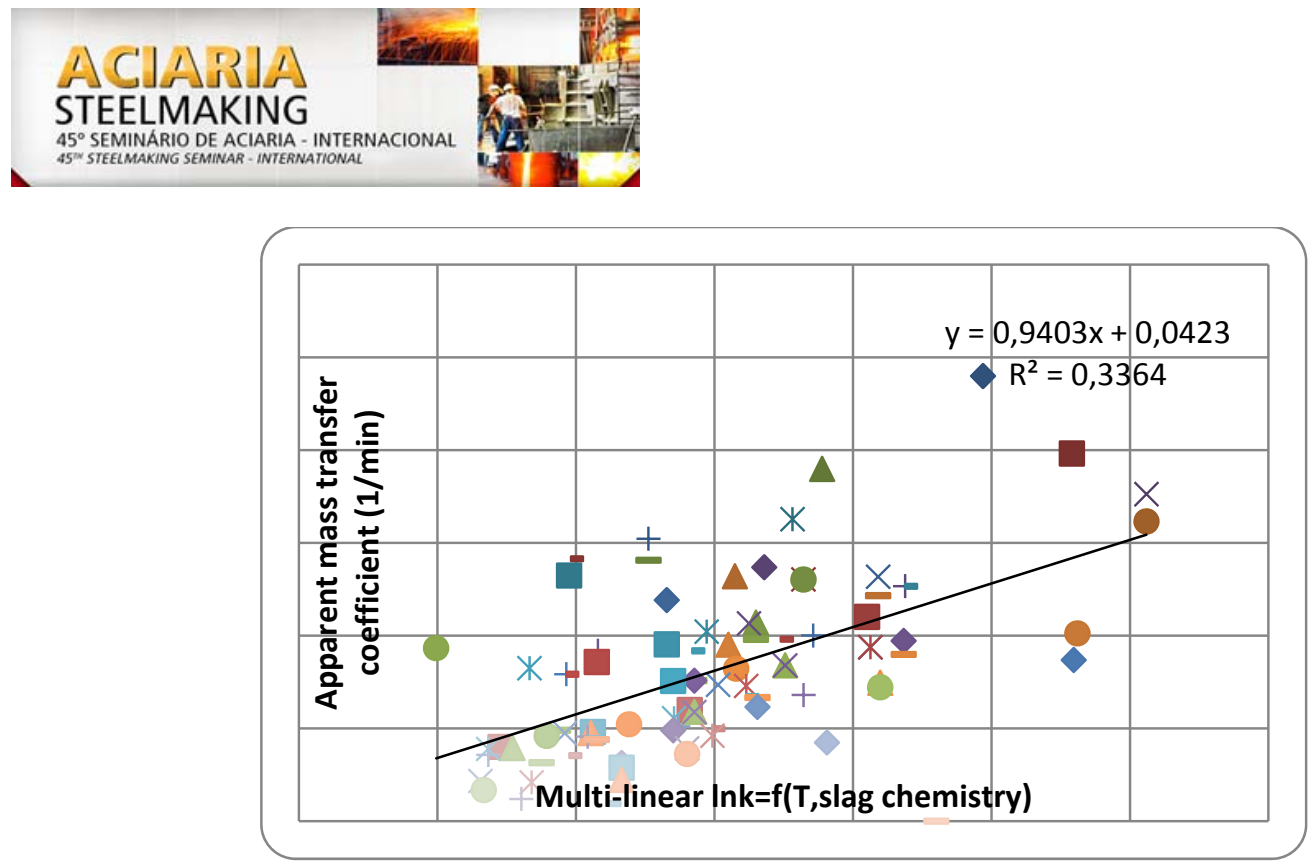

Figure 8. Actual apparent mass transfer coefficient as correlated with Temperature and slag chemistry, i.e.: $\ln (k)=15.64-0.0009 \cdot T-0.076 \cdot(\% \mathrm{CaO})+0.391 \cdot(\% \mathrm{MnO})+0.193 \cdot(\% \mathrm{SiO} 2)$

\section{CONCLUSIONS}

As per the CFD results, it was observed two groups of recipes with a very distinct mixing time: group 1 composed by recipes $1,2,3,4$, and 7 reproduced the lowest mixing time. Among these, recipe 3 was the best one. All other have very similar results.

It was observed in group 1 uniform flow rate recipes CFD simulation that there was no significant difference in mixing times between low POABB flow rate and higher one.

Non-uniform flow recipes, which composed group 2, involving a relatively smaller total flow rate, produced unfavorable mixing condition for the current configuration of bottom plugs. Therefore, it seems that the benefits of non-uniform recipes as reported in literature cannot be generalized. A case-by-case approach needs to be followed to evaluate each bottom stirring system.

The CFD results are consistent with the theory of surface renewal originally proposed by Dankwerts. Therefore, CFD results could be explained by recognizing the fact that the mixing time is regulated by the turbulent kinetic energy available to stir the bath and more particularly by the creation of higher interfacial area (via stretching and folding of fluid elements) as a result of argon injection through the bottom plugs.

Industrial trial results have shown a higher phosphorus partition coefficient $(L p)$ when adopting POABB process. This result suggests that metal-slag mixing plays a very important role during this process. However, to achieve a consistent low end point $P$ low temperature and reduction of $L p$ scattering is required.

Comparison between actual $L p$ obtained after POABB trials and equilibrium one indicates that there is still a room to improve $P$ removal.

Within the range of flow rate tested, an analysis based on apparent mass transfer coefficient has not shown a strong correlation with stirring power. This results is in good agreement with CFD one, where constant low flow rate and higher one resulted in similar mixing time. Therefore another kinetic limiting step may be taking place.

A slag mass transfer controlling step for $P$ removal was discharged as long as an inconsistent trend of increasing $k_{a}$ with increase slag viscosity was observed.

The temperature dependent apparent $P$ mass transfer coefficient suggests that $P$ reaction kinetic might play an important role in $\mathrm{P}$ removal at Tubarão site. However,

* Technical contribution to the $45^{\text {th }}$ Steelmaking Seminar, May $25^{\text {th }}-28^{\text {th }}, 2014$, Porto Alegre, RS, Brazil. 
slag composition effect on $k_{a}$ requires a deeper analysis in order to have its mechanism clarified.

\section{REFERENCES}

1 Fruehan RJ. The Making Shaping and treating of steel. $11^{\text {th }}$ ed. Pittsburgh: AISE steel Foundation; 1999.

2 Zhang X, Xie B, Li HY, Diao J. Couple reaction kinetics of duplex steelmaking process for high phosphorus hot metal. Ironmaking and Steelmaking. 2013;40(4):282-9.

3 Zhi-Hong T, Tian Z, Li B, Zhang X, Jiang Z. Double Slag dephosphorization in BOF for Producing Low Phosphorus Steel. Journal of iron and Steel research, International. 2008;16(3):6-14.

4 Turkdogan ET. Assessment of $\mathrm{P}_{2} \mathrm{O}_{5}$ Activity Coefficients in Molten Slags. ISIJ International. 2000;40(10):964-70.

5 Basu S, Lahiri AK, Seetharaman S. A model for Activity Coefficient of $\mathrm{P}_{2} \mathrm{O}_{5}$ in BOF slag and $P$ distribution between liquid steel and slag. ISIJ International. 2007;47(8):1236-8.

6 Basu S, Lahiri AK, Seetharaman S. Phosphorus partition between liquid steel and $\mathrm{CaO}-$ $\mathrm{SiO} 2-\mathrm{FeO}_{x}-\mathrm{P}_{2} \mathrm{O}_{5}-\mathrm{MgO}$ slag containing 15 to $25 \% \mathrm{FeO}$. Metallurgical and Materials transaction B. 2007;38B:623-30.

7 Chen C, Zhang L, Lehmann J. Thermodynamic Modeling of Phosphorus in steelmaking Slags. High Temp. Mater. Proc. 2013;32(3):237-46.

8 Chang K, Huang C, Huang W, Liu Y. Investigation of microstructure and phosphorus distribution in BOF slag. China Steel technical Report. 2008;21:1-6.

9 Parreiras HF, Carneiro CAR, Araújo TCS. Estudo Microestrutural da escória de convertedor LD e sua relação com o processo de desfosforação. In: Anais do $44^{\circ}$ Seminario de Aciaria; 2013, Araxá, Minas Gerais. São Paulo: ABM; 2013. p.491-501.

10 Deo B, Haltder J, Snoeijer B, Overbosh A, Boom R. Effect of MgO and Al2O3 variation in oxygen steelmaking (BOF) slag on slag morphology and phosphorus distribution. Ironmaking and steelmaking. 2005;32(1):54-60.

11 Basu S. Studies on dephosphorization in steelmaking [doctoral thesis]. Stockholm: School of industrial engineering and management, Department of materials science and engineering, Division of materials science process, Royal Institute of Technology; 2007.

12 Jung I. Overview of the applications of thermodynamic databases to steelmaking process. Calphad: Computer Coupling of Phase Diagram and Thermochemistry. 2010;34:332-63.

13 Lehmann J, Bonnet F, Bobadilla M. Thermodynamic description of Liquid steels and Metallurgical Slags by a Generalization of the "Central Atom" Model. Iron and steel Technology. 2006;3(4):115-23.

14 Lehmann J, Zhang L. The generalized central Atom for metallurgical slags and high Alloyed Steel Grades. Steel research International. 2010;81(16):875-79.

15 Basu S, Lahiri AK, Seetharaman S. Change in phosphorus partition during Bowing in a commercial BOF. ISIJ International. 2007;47(5):766-8.

16 Singh V, Lenkas N, Ajmani S K, Bhanu C, Phathak S. A Novel Bottom Stirring Scheme to improve BOF performance through Mixing and mass transfer Modelling. ISIJ International. 2009;49(12):1889-94.

17 Odental H, Falkenreck U, Shlüter J. CFD simulation of multiphase melt flow in steelmaking converters. European Conference on Computer Fluid Dynamics. Netherland; 2006.

18 Ansys Fluent Manual, Release 14.5.7. Canonsburg: ANSYS Inc.; 2013.

19 Dankwerts PV. Continuous flow System. Distribution of Residence time. Ind. Eng. Chem. 1951;43:1460-67.

20 Manning C, Fruehan J. The role of the Phosphorus reaction between liquid iron and Slag. Metallurgical and materials transaction B. 2013;44B:37-44.

* Technical contribution to the $45^{\text {th }}$ Steelmaking Seminar, May $25^{\text {th }}-28^{\text {th }}, 2014$, Porto Alegre, RS, Brazil. 